\title{
A DISCURSIVIZAÇÃO DO FEMININO E SUAS RELAÇÕES COM A DOCÊNCIA: MEMÓRIA E ATRAVESSAMENTOS DISCURSIVOS
}

\author{
CAMILA CARRARI DORNELAS; FILOMENA ELAINE P. ASSOLINI \\ Faculdade de Filosofia, Ciências e Letras de Ribeirão Preto \\ Universidade de São Paulo \\ Av. Bandeirantes, 3900 - 14040-030 - Ribeirão Preto - SP - Brasil \\ carrarieusp.br ; elainefdoceffclrp.usp.br
}

\begin{abstract}
Resumo. A presença das mulheres na profissão docente é historicamente (re)conhecida. Esse acontecimento foi permeado pela ideologia dos atributos "necessários" para se educar, que coloca a referência docente no feminino, na mulher e na mãe. Este trabalho inscreve-se nos campos teóricos da Análise do Discurso de matriz francesa, da Psicanálise freudo-lacaniana e das Ciências da Educação, discutindo as memórias discursivas presentes nas imagens que circulam na rede social Facebook, analisando os sentidos produzidos sobre o feminino e a prática docente.
\end{abstract}

Palavras-chave: feminino; docência; Análise do Discurso francesa.

\begin{abstract}
The presence of women in teaching positions is historically acknowledged. This situation is permeated by the ideology of the "necessary" attributes for teaching, which establish feminine teaching models, i.e. the woman and the mother. This work is framed within the field of Discourse Analysis of French approach, Freudian-Lacanian Psychoanalysis and Education Research. The aim of this work is to highlight and analyze discursive memories in the images circulating in the social network Facebook as well as the meanings produced about the feminine associated to teaching practice.
\end{abstract}

Keywords. female; teaching; French Discourse Analysis.

\section{Introdução}

É conhecida a massiva presença da mulher na profissão docente. Historicamente, a relação das mulheres com o campo da educação foi permeada pela ideologia da vocação e dos atributos "necessários" para se educar que, substancialmente, coloca a referência docente no feminino, na mulher ou na mãe. Portanto, ao abordar essa questão, é pertinente observarmos que nos discursos sobre a profissão docente, a mulher e a mãe se atravessam e entrecruzam.

Inúmeros trabalhos (ALMEIDA, 1998; SILVA, 2002) contribuem significativamente no sentido de investigar esse fenômeno tanto quantitativa quanto qualitativamente. No entanto, a chamada feminização do magistério não se refere exclusivamente à forte presença das mulheres na profissão docente, mas, também, à 
associação das atividades e significados dessa profissão ao universo feminino ao longo da história.

No início do século XX, devido à forte expansão industrial, o discurso sobre a importância do trabalho da mulher impulsiona as mesmas para determinados setores considerados apropriados para o seu sexo, como a saúde e a educação.

O incentivo à participação da mulher nas escolas normais atendia os interesses das políticas públicas que postulavam a missão patriótica e civilizatória das mulheres atuantes como mães e educadoras. Com as dificuldades de acesso à educação, o ideário sexista e paternalista vigente, estudar e ter a possibilidade de reger uma classe tornou-se a única oportunidade de as mulheres continuarem seus estudos e de terem um pouco mais de visibilidade social. Inicia-se o processo denominado feminização do magistério (SILVA, 2002).

Essa situação contribuiu para a desvalorização da função docente, que ainda é exercida e tem seu espaço nos dias atuais. Embora ao longo dos anos muitas conquistas tenham sido alcançadas do ponto de vista do protagonismo feminino, e discussões sobre a profissão docente e a feminização do magistério tenham sido aventadas, há naturalização dos discursos sobre a mulher e sua participação social e econômica. Esses discursos representam a mulher na posição de mãe, valorizando a maternagem e colocando-a, quase sempre, em posição inferiorizada, na hierarquia das relações entre masculino e feminino, conforme mostraremos nas análises discursivas, a serem realizadas adiante.

A convivência, através de séculos, com um modelo naturalista de diferenciação sexual e as mudanças históricas no ser e fazer dos homens e das mulheres, atravessados por componentes ideológicos, impulsionados pela política e economia, compõem marcas nos discursos atuais, que, muitas vezes, passam despercebidas. É preciso, portanto, a partir do próprio discurso (e dos efeitos de sentidos produzidos), lançar luz a essas questões, analisando-as com o intuito de "desconstruir" o que está naturalizado, e os estereótipos que, por vezes, caracterizam os modos de produção de conhecimento.

Sendo assim, trazemos resultados de uma pesquisa que investigou a discursivização do feminino e da docência em redes sociais. Buscamos compreender, especificamente, como o feminino e a docência estão imbricados, como são tratados, falados e imaginados no espaço cibernético.

Para tanto, valemo-nos da Análise do Discurso de matriz francesa (AD), da Psicanálise freudo-lacaniana e dos estudos das Ciências da Educação, particularmente, os que dizem respeito à formação de professores.

O presente artigo está assim organizado: em um primeiro momento apresentamos as bases centrais da $\mathrm{AD}$ (e alguns pressupostos da Psicanálise), posteriormente, iremos nos deter na constituição do corpus e na construção do dispositivo analítico. Em seguida, apresentamos análises discursivas nascidas a partir de nossos gestos interpretativos. Lembramos que tais gestos são sempre inacabados, posto que haverá outros sentidos a serem revelados, perscrutados, escavados. Não são definitivos, portanto. 


\section{A Análise de Discurso como referencial teórico e metodológico}

A escolha de um campo teórico-metodológico que vá ao encontro das complexidades do sujeito, tomando o discurso como maior base de sustentação, se coloca como tarefa fundamental. Através do discurso, acreditamos ser possível acessar o que há de singular no sujeito, ou seja, o inconsciente, assim como as marcas sociais e históricas que o caracterizam. Para isso, optamos pela Análise do Discurso de matriz francesa, AD, tendo Michel Pêcheux como fundador e um dos estudiosos mais profícuos desse campo.

A $\mathrm{AD}$, como um referencial teórico-metodológico surgido na década de 60 do século $\mathrm{XX}$, toma o discurso como seu objeto próprio: a língua funcionando para a produção de sentidos (ORLANDI, 2012, p.17).

É um campo que se inscreve num quadro que articula o linguístico com o social e estendendo-se para outras áreas do conhecimento.

[...] a Análise do Discurso é herdeira das três regiões de conhecimento - Psicanálise, Linguística, Marxismo - não o é de modo servil e trabalha uma noção - a de discurso - que não se reduz ao objeto da Linguística, nem se deixa absorver pela teoria Marxista e tampouco corresponde ao que teoriza a Psicanálise. Interroga a Linguística pela historicidade que ela deixa de lado, questiona o Materialismo perguntando pelo simbólico e se demarca da Psicanálise pelo modo como, considerando a historicidade, trabalha a ideologia como materialmente relacionada ao inconsciente sem ser absorvida por ele. (ORLANDI, 2012, p. 20)

Dessa forma, a AD tem como foco principal o discurso e suas inter-relações do real, do social, com o sujeito histórico. O sujeito da $\mathrm{AD}$, portanto, é um sujeito marcado por espaço e por tempo determinados. Como sua fala é produzida desse determinado lugar e tempo, a concepção de um sujeito histórico articula-se à concepção de um sujeito ideológico.

É um sujeito afetado pela língua e atravessado pela ideologia. A ideologia é condição para a constituição desse, de modo que, interpelado por ela, produza o dizer. Ao dizer, dar sentido e interpretar (ao mesmo tempo em que nega essa interpretação), naturaliza o que é produzido na relação do histórico e do simbólico.

Althusser (1996) irá relacionar o termo aos Aparelhos Ideológicos do Estado, justificando que, para que a classe dominante perpetue sua dominação, essa vem gerar mecanismos de reprodução das condições materiais, ideológicas e políticas de exploração. Para o autor, a ideologia é "uma 'representação' da relação imaginária dos indivíduos com suas condições reais de existência" (p. 126). Como é uma relação imaginária, o homem cria e representa simbolicamente na sua relação com a realidade, no entanto, por ser simbólica e abstrata, acaba por se distanciar da realidade objetiva.

O que "os homens" "representam para si" na ideologia não são suas situações reais de existência, seu mundo real; acima de tudo, e sua relação com essas condições de existência que se representa para eles na ideologia. É essa relação que está no centro de toda representação 
ideológica, portanto imaginária, do mundo real. (ALTHUSSER, 1996, p. 127)

Pêcheux (1995) avança essa proposição, discutindo o funcionamento da(s) ideologia(s) e a interpelação do indivíduo em sujeito, pela ideologia e pelo discurso. Para o autor, a ideologia interpela o indivíduo em sujeito e se realiza através do complexo das formações ideológicas que 'fornece a 'cada sujeito' sua 'realidade', enquanto sistema de evidências e de significações percebidas - aceitas - experimentadas” (p. 162).

Essa interpelação se dará pela identificação do sujeito com a formação discursiva que o domina, que o constitui como sujeito, e que, por sua vez, se reinscreverá no seu próprio discurso. No discurso dos sujeitos, a materialidade concreta da instância ideológica existe sob a forma de formações ideológicas, que, ao mesmo tempo, possuem um caráter 'regional' e comportam posições de classe (PÊCHEUX, 1995). Assim, a materialidade ideológica só é possível de ser apreendida a partir da materialidade linguística.

Toda ideologia, portanto, é responsável por constituir indivíduos em sujeitos. A ideologia é necessária na relação entre linguagem e mundo e a tarefa da $\mathrm{AD}$ é refletir sobre essas relações materializadas e presentes no discurso.

O sujeito discursivo, determinado pela língua e pela história, ocupa um lugar, uma "posição" (ORLANDI, 2012) para ser sujeito do que diz. Assim, o sujeito pode ocupar a posição (onde não tem acesso direto ao interdiscurso que o constitui) de mulher, mãe, professor. Ao falar de uma posição, revela sua identidade, sempre em relação a outras posições.

Já o sujeito na Psicanálise também não é o indivíduo ou o eu. A partir de 1920, Freud introduz novas noções sobre o sujeito, (re)afirmando seu descentramento. Lacan (1995) dirá que, “com Freud faz irrupção uma nova perspectiva que revoluciona o estudo da subjetividade e que mostra justamente que o sujeito não se confunde com o eu" (p. 16). O sujeito psicanalítico é marcado, cindido e atravessado pelo inconsciente.

No decorrer do seu ensino, Lacan mostra que é a linguagem que determina a existência do sujeito, tornando-o dependente e assujeitado ao campo simbólico.

Assim é que, se o homem chega a pensar a ordem simbólica, é por estar primeiramente aprisionado nela em seu ser. A ilusão de que ele a formou com sua consciência provém de ter sido através de uma hiância específica de sua relação imaginária com o semelhante que ele pôde entrar nessa ordem como sujeito. Mas ele só pôde fazer essa entrada pelo desfilamento radical da fala. (LACAN, 1998, p. 57)

Para Lacan (1998), o sujeito se encontra onde o discurso desliza. O sujeito fala o outro, que lhe empresta falso significado (o significante transita numa cadeia assumindo um valor que não está diretamente ligado ao significado) e, portanto, a linguagem procura de todas as maneiras sustentar uma compreensão que, na verdade, é falsa, porque é construída a partir da ilusão. É onde o discurso desliza, escorrega, que é possível desconstruir um percurso. É na lacuna do discurso, na desconstrução, que vamos encontrar o sujeito (MAGGI, 2002, p. 94-95). 
Seguindo esse raciocínio, não se trata, pois, de definir o sujeito da Psicanálise ou da $\mathrm{AD}$, porque ele é indefinível, posto que o sujeito vai deslizando de significante em significante pelo conjunto da linguagem que compõe o Outro (inconsciente), assim como discursa dessa ou daquela determinada posição. O sujeito é um vazio, "um furo na linguagem" (QUINET, 2012, p. 23). Ou seja, só se é mulher em relação ao homem ou a uma criança; se é professor em relação a um médico ou em relação a um engenheiro.

É importante ressaltar que o sujeito, para a $\mathrm{AD}$, é uma posição material linguístico-histórica, produzida em meio ao jogo de contradições e tensões socioideológicas. Ou seja, em uma dada análise, busca-se compreender o modo de produção de sentidos resultante das posições discursivas de sujeito constituídas. Lacan, por sua vez, não negligencia a história, embora privilegie o significante como elemento primordial no processo de constituição do sujeito (MARIANI, 2003, p. 61).

Cabe salientar, também, que o discurso não é uma materialidade fixa, rígida, imutável. Os discursos produzem efeitos de sentido que são complexos e múltiplos, e que se evidenciam através de marcas linguístico-discursivas, manifestações que o constituem, que advêm do sujeito, seu inconsciente, seu tempo histórico, do social e da ideologia (condições de produção). Assim, pode-se dizer que os sentidos não existem em si mesmos, mas são determinados pelas posições ideológicas em um processo sóciohistórico, no qual se produz o discurso.

A formação discursiva está intimamente relacionada à noção de formação ideológica, já que o discurso se constitui a partir dos efeitos de sentido produzidos, enquanto o que o sujeito diz se inscreve em uma formação discursiva e não em outra que, por sua vez, representa no discurso as formações ideológicas. A formação discursiva se define como aquilo que numa formação ideológica dada - a partir de uma posição dada em uma conjuntura sócio-histórica dada - determina o que pode e deve ser dito (ORLANDI, 2012, p. 43).

Não existe homogeneidade na composição das formações discursivas, pois essas são constituídas por contradições. Palavras idênticas significam diferentemente ao se inscreverem em formações discursivas diferentes que, por sua vez, também se dão em condições de produção diferentes.

Relacionado a essa exterioridade, o discurso também se vincula a outros discursos, o interdiscurso, entendido aqui como "aquilo que fala antes, em outro lugar, independentemente" (ORLANDI, 2012, p. 31). É o saber discursivo que torna possível todo o dizer e que retorna sob a forma do pré-construído, do já-dito.

"O fato de que há um já-dito, que sustenta a possibilidade mesma de todo dizer, é fundamental para se compreender o funcionamento do discurso, a sua relação com os sujeitos e com a ideologia" (idem, p. 32). É a observação do interdiscurso que permite remeter um dizer a toda uma filiação de dizeres, a uma memória, a uma historicidade.

No discurso, circulam formulações já enunciadas anteriormente que funcionam como estruturação da materialidade discursiva, se estendendo em uma dialética da repetição e da regularização: "a memória discursiva seria aquilo que, face a um texto que surge como acontecimento a ler, vem restabelecer os 'implícitos' [...] de que sua leitura 
necessita: a condição do legível em relação ao próprio legível” (PÊCHEUX, 2010, p. 52). Nessa linha de pensamento, destacamos que a memória não pode ser percebida como homogênea. Em consonância com Pêcheux (2010), salientamos que a memória não é uma esfera plana, cujas bordas seriam transcendentais históricos ou o conteúdo com sentido fixo, estável, homogêneo, acumulado como um reservatório. A memória é um espaço móvel de divisões, de deslocamentos e retomadas, de conflitos, polêmicas e contradiscursos.

As posições sociais ocupadas pelos sujeitos e o lugar a partir do qual ele fala também são constitutivos do que ele diz, caracterizando uma relação de forças. Nossa sociedade é caracterizada por relações hierarquizadas que sustentam um poder que advém de diferentes lugares: lugar de homem e de mulher, de adulto e de criança, de professor e de aluno, por exemplo. Nesse caso, não são os sujeitos e nem seus lugares na sociedade que funcionam no discurso, mas a imagem que é resultado de suas projeções. Podemos dizer que o sujeito produz um discurso que é resultado da imagem que possui do outro. Discursamos a partir de formações imaginárias.

Para Orlandi (2012), as condições de produção implicam o que é material (a língua e seus equívocos e a historicidade), o que é institucional (a formação social) e o mecanismo imaginário. É esse mecanismo que produz imagens dos sujeitos dentro de uma conjuntura sócio-histórica. É um jogo imaginário que preside a troca de palavras.

Destarte, nesse jogo complexo que constitui o discurso, formações imaginárias, formações discursivas e formações ideológicas estabelecem forte ligação entre si. A imagem não é resultado que advém somente do sujeito, mas também do social, englobando as formações discursivas e as formações ideológicas.

É por meio da análise da materialidade do discurso que podemos atravessar o imaginário que condiciona os sujeitos em suas discursividades e, explicitando o modo como os efeitos de sentido são produzidos, compreender melhor o que está sendo dito, referindo-os às suas condições de produção, estabelecendo as relações que os sentidos mantêm com a memória e, também, remetendo-os a uma formação discursiva - e não outra - para a compreensão do processo discursivo (ORLANDI, 2012).

\section{Análises Discursivas: olhares e gestos interpretativos}

Os efeitos de sentidos circulam e se materializam em textos e imagens. $\mathrm{Na}$ sociedade atual, entre os espaços de produção e circulação de discursos e sentidos, as redes sociais têm alcançado, cada vez mais, enorme importância. A rede social Facebook sustenta inúmeros "perfis" e "comunidades" que se centram na temática e no fazer docente. Diariamente, esses perfis compartilham imagens que discursam sobre a profissão de professor que são replicadas e recompartilhadas por toda a rede social, fazendo circular sentidos sobre o ser e fazer docente que merecem, portanto, a nossa atenção.

É importante esclarecer que, de acordo com a perspectiva discursiva, só podemos falar em corpus a partir de um recorte de dados determinado pelas condições de produção, 
levando-se em conta os objetivos e princípios teóricos que, orientando toda a análise, possibilitaram uma leitura não subjetiva dos dados. Segundo Orlandi, “[...] o recorte é uma unidade discursiva; fragmento correlacionado de linguagem e situação" (1987, p. 139).

Vale ressaltar também que os dados são entendidos, aqui, “[...] como elementos indiciários de um modo de funcionamento discursivo" (TFOUNI, 1992, p. 206).

Partindo do princípio de que o discurso é um acontecimento (PÊCHEUX, 1990) e que implica uma historicidade e os sentidos daí decorrentes, propomos, neste trabalho, a análise do acontecimento discursivo no campo da memória discursiva de imagens.

Avançando com a nossa discussão, ressaltamos que tanto a trajetória histórica que reflete as condições de trabalho, educação e família - quanto o paradigma da diferença sexual e a igualdade de direitos - que postulam sobre o ser e fazer do homem e da mulher - trazem elementos importantes para o entendimento da relação que se estabelece entre o feminino e a profissão docente. Contribuem também, para observarmos a construção de uma memória histórica e discursiva, que estabelece ecos e reverberações nos discursos atuais.

Historicamente, foi com o desenvolvimento da propriedade privada e das sociedades de classe que passam a existir, mais marcadamente, a desigualdade social jurídica entre homens e mulheres, sobretudo com relação ao casamento que, nas sociedades greco-romanas, se constituía a partir de um arranjo político/econômico.

Prevalecia, na Antiguidade Clássica, o modelo de sexo único e de uma relação hierárquica entre o homem e a mulher. Foi Aristóteles quem concebeu a geração como diversamente distribuída entre as figuras do homem e da mulher e estabeleceu os alicerces fundamentais do ideário de sexo único. Essa leitura se desdobraria em outras, de polarização do masculino e feminino (BIRMAN, 2001).

Com a Revolução Industrial Inglesa e, posteriormente, a Revolução Francesa, importantes etapas para a construção do mundo burguês, ocorrem impactos também na organização familiar. A criança passa a ter mais visibilidade social e a preocupação com sua educação emerge e ganha consistência.

Concernente a isso, o modelo de um sexo único fundado nas questões da geração e reprodução, passa a dar lugar ao paradigma da diferenciação sexual, baseado numa visão naturalista da diversidade sexual (essências diferentes e naturezas inconfundíveis) que delineariam as possibilidades e as finalidades sociais diversas para os sexos.

[...] a nova democracia advinda da Revolução Francesa procurou fundar na natureza biológica as inserções sociais diferentes entre os sexos. [...] a moderna democracia transformou efetivamente os fundamentos até então inquestionáveis do poder patriarcal, mas manteve inalteradas as fontes do poder masculino. Para isso, entretanto, foi necessário forjar um novo discurso, precisamente sobre a diferença sexual, pelo qual o homem e a mulher teriam finalidades e inserções sociais bastante diversas, em consequência de suas naturezas diferenciadas e irredutíveis, uma à outra. (BIRMAN, 2001, p. 49; grifo do autor) 
Assim, com essa leitura naturalista e biológica da diferença entre os sexos, há apenas um deslocamento da hierarquia entre os mesmos, que não deixou de existir, mas é causa de um determinismo natural dos corpos.

O que destacamos nesse paradigma da diferenciação sexual são os aspectos que envolvem a maternidade. A construção exclusiva e restrita do ser e fazer da mulher em torno da figura da mãe e da finalidade específica de reprodução da espécie humana, fundamenta, de maneira irrefutável, a concepção da diferença sexual.

Lembramos que a Psicanálise, com o discurso freudiano, vem se inscrever de maneira inédita na história da sexualidade no Ocidente, pois apresenta a feminilidade como sendo a origem e o fundamento do sexual, a sua condição de possibilidade, diferentemente da masculinidade, como se pensava na tradição aristotélica e galênica que produziu o modelo de sexo único (BIRMAN, 1999).

Foi Freud (2006), ao debruçar-se sobre os sintomas histéricos, que presume que a histeria seria a impossibilidade de aceder ao feminino ou, ainda, a rebelião que se manifesta em face do lugar materno atribuído à mulher, desde o século XVIII, engendrando uma discussão sobre o enigma que a feminilidade carrega, longe de lhe dar fechamento.

No referencial teórico da Psicanálise, a feminilidade da mulher deriva de seu "ser castrada": mulher é aquela cuja falta fálica a incita a se voltar para o amor de um homem, primeiro o pai, depois o cônjuge. Lacan avança nessa construção teórica, ao introduzir uma nova distinção. Não se trata de "ter ou não ter" o falo (uma lógica binária), mas "ser o falo". A mulher, convocada ao lugar do objeto, graças ao desejo do parceiro, converte sua falta num efeito compensatório: a mulher se transforma no que não tem. Por essa admissão, em Lacan, a falta feminina já é positivada. A mulher é invenção da cultura, marcada pela história e que, por isso mesmo, inacabada, muda de feição através dos tempos (SOLER, 2006).

Dessa maneira, podemos identificar, nos postulados lacanianos, as condições de avanço e atualidade no tocante aos estudos sobre o feminino. Ao mudar as condições históricas e sociais e as condições de produção, mudam-se também o ideário e os discursos proferidos sobre a mulher.

Com relação aos aspectos que envolvem a educação, essa se estabelece também focada na hierarquização dos sexos, sustentada pelo paradigma naturalista da diferenciação sexual. A educação feminina, na verdade, adquire papel fundamental para a manutenção do pensamento dominante e de hierarquia entre os sexos.

No Brasil, a mulher só adquiriu o direito à educação quando, em 15 de outubro de 1827, através de lei, criam-se as escolas de primeiras letras para meninas e, como consequência disso, o surgimento das primeiras vagas para o sexo feminino no magistério primário, sustentado pelo ideário de uma função materna, um dom, uma vocação pertencentes ao feminino.

Em 1830, um projeto de lei estabelecia preferência às mulheres para o ensino no magistério primário das escolas públicas. É a partir desse momento que se inicia a criação 
das escolas normais, que vinham ao encontro das necessidades de melhoria do ensino ministrado, porém, no início, as mesmas destinavam-se somente aos homens (SILVA, 2002, p.83).

No início do século $\mathrm{XX}$, diante da expansão industrial, o discurso sobre a importância do trabalho da mulher (carregado da ideologia de "atributos necessários" e de uma "vocação" ou "missão") impulsiona-as para determinados setores considerados apropriados para seu sexo, como a saúde e a educação, explicando, portanto, a íntima relação do gênero feminino com a docência.

\section{CASE-SE COM UMA PROFESSORA!}

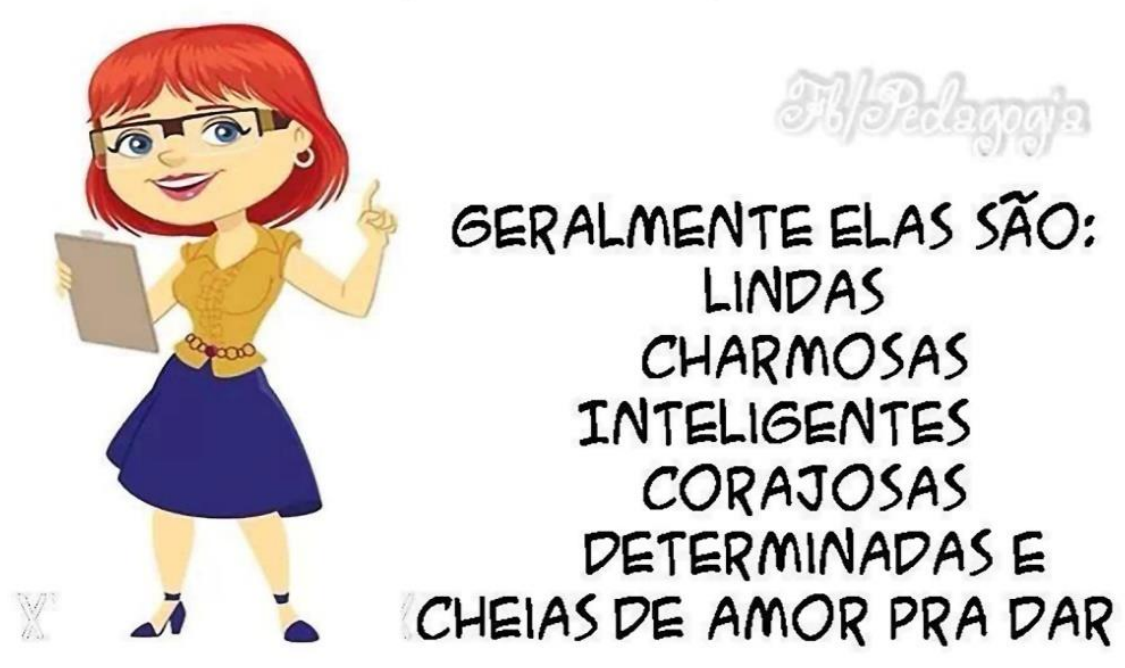

Recorte 1: Imagem retirada do Facebook. Fonte: Professores Criativos, 2015.

O recorte 1 apresenta uma figura feminina que apresenta óculos e uma prancheta na mão e associam à figura do professor um caráter intelectualizado. Isso pode indicar que, como o discernimento entre o feminino, o materno e o fazer pedagógico é um tanto obscuro, surgiria a demanda de um "carimbo" científico que legitimasse um fazer pedagógico.

Essa obscuridade sustenta-se num estereótipo criado sobre a existência de uma íntima ligação entre a educação dos filhos e a mulher e foi fundamental para que no século XX, houvesse a "transferência" da responsabilidade da mulher com a educação doméstica para a educação escolar (SILVA, 2002, p.74).

Contrariamente à ideia da tentativa de cientifizar o fazer pedagógico; o enunciado principal convoca à finalidade do matrimônio. Historicamente, a educação feminina se desenrolou no sentido da esfera privada para a pública muito lentamente. 
No século XIX, “o ideal era: ensinar, sim, mas não muito, apenas o suficiente para serem boas mães e esposas" (SILVA, 2002, p.83). Assim, as moças provenientes de famílias abastadas eram enviadas para cursar a escola e, com poucos anos de educação, eram retiradas precocemente para, então, se casarem.

No idos do século XIX e início do século XX, o casamento, atrelado a uma noção de "natureza feminina", é um destino tido como praticamente incontestável.

Nas formações ideológicas concernentes à instituição casamento, as mulheres são assim definidas como esposas, mães e "rainhas do lar" em potencial. Há uma ênfase nos "incontestáveis papéis femininos", especialmente quando se referem às jovens. Se o casamento é considerado a porta de entrada para a realização dos ideais de feminilidade, as moças precisam ser educadas para que não se desviem desse caminho e não escapem do futuro reservado à mulher, ou seja, o casamento (PINSKY, 2014).

Durante muitos anos a educação, focada na hierarquização dos sexos e intimamente relacionada à imagem do papel social da mulher (fortemente atrelado ao objetivo do matrimônio e da maternidade), foi concretizada no trabalho doméstico e na reprodução.

Essa memória se inscreve em formações discursivas e imaginárias que atualizam o discurso e naturalizam os sentidos atrelados ao educar como sendo um fazer quase exclusivamente de mulheres e sugerem uma memória que atualiza os discursos, onde a profissão docente surge e se desenvolve de maneira não especializada, o que demandaria, então, como apresentado na imagem, a tentativa de uma legitimação científica.

Embora seja possível observar o deslocamento de sentidos no discurso funcionando como acontecimento, determinado por condições de produção que são enunciativas e sócio-históricas, observa-se, também, o uso de genéricos discursivos que eternizam a profissão de professor num fazer próprio do feminino (e de características associadas ao gênero), e que servem como um chamamento para que o professor assuma esse lugar.

O uso do genérico discursivo (TFOUNI, 2010) implica caráter anônimo que advém de uma estrutura linguística específica, que se caracteriza por ser marcada sintaticamente pela não identificação do enunciador empírico, o que se traduz pelo uso do sujeito indeterminado ou impessoal. Assim, "Não importa quando, quem, nem onde ou para quem esse genérico se dirija; seu efeito de sentido é exatamente o mesmo" (TFOUNI, 2010, p. 78; grifo do autor).

Dessa forma, no genérico imperativo "Case-se com uma professora!", tanto enunciador como receptor ficam anônimos. Tfouni \& Tfouni (2007) chamam a atenção para o fato de que a construção em forma de lei, generalizante, confere aos genéricos um caráter de universalidade. Isso faz parecer que eles asseveram uma verdade válida a todos. Existe, portanto, nos genéricos uma tentativa de apagamento da subjetividade, o que impede outras interpretações possíveis, produzindo efeito de transparência de sentido e colocando, forçosamente, o ouvinte, no caso o leitor do texto e da imagem, em uma determinada posição em relação à ideologia. 
No genérico, aqui discutido, há o apagamento de que, em alguns contextos ou situações, existam professores que sejam do sexo masculino, que possam existir professoras que não desejam se casar ou que existam pessoas que não queiram se casar com uma professora. Esconde, ainda, o fato que casamento e profissão docente existam como instâncias separadas.

Há, ainda, a obliteração de que nem todas as professoras teriam as qualidades descritas posteriormente como "boas" características em uma professora (ou em uma mulher) e que outras características existam e sejam importantes no fazer docente. Mais ainda, que essas características não seriam questionáveis e totalmente verossímeis e necessárias, sendo consideradas eletivas para se tornar uma professora ou, como apresentado na formação discursiva na imagem, contrair um casamento. Assim,

vê-se aí, do ponto de vista discursivo, uma tentativa de apagar o nãodito que necessariamente sempre acompanha o dito. Do mesmo modo, as condições de produção dos enunciados genéricos são cerceadas, o que impede que a interpretação abra-se para outras possibilidades e também que a dialogia se instale. Por estes motivos, temos nos genéricos discursos do tipo autoritário. (TFOUNI, 2007, p. 301)

O que se observa é que, através da memória inscrita nas formações discursivas, busca-se eternizar a profissão de professor num fazer próprio do feminino e ao instituir o genérico como chamamento para que o sujeito assuma seu lugar, coloque a profissão de professor profundamente arraigada a um ideário construído historicamente de uma profissão eminentemente feminina e de "espera-marido", que reúne qualidades consideradas de boa mãe, mulher e professora.

Retomando a sequência do enunciado que, após uma generalização, apresenta adjetivos à figura feminina ("lindas, charmosas, inteligentes, corajosas, determinadas e cheias de amor para dar") é importante notar que, historicamente, esses atributos já foram polarizados numa lógica binária entre os sexos.

O modelo naturalista de diferença entre os sexos impôs ao homem e à mulher finalidades e inserções sociais, assim como atributos e qualidades bastantes diversas uma da outra. Beleza e charme eram associados à figura feminina, com pouca participação intelectual e social; enquanto que atributos como coragem e determinação já foram associados à figura masculina, num sistema claramente androcêntrico.

De acordo com Moreira (2012), "graça" e "sedução" são marcas, paradoxalmente fortes, do feminino. Se em casa, antes de serem enviadas aos conventos, as meninas eram educadas para ser e se vestirem com graça e delicadeza, com vestimentas ricas em detalhes e adereços, ao ingressarem nos conventos ou escolas, todo esse investimento ao redor do ser e se vestir, deveria ser retirado, pois poderia provocar a cobiça dos homens, o que era considerado extremamente inadequado. Os atributos femininos deveriam ser substituídos por uniformes austeros e padronizados. "Crescem as meninas com este conflito existencial: o encanto como manifestação da pureza, e a sedução como tradução do pecado; seduzir (persuadir, iludir) ou encantar (maravilhar, atrair, fascinar pela beleza)" (p. 3221). 
Na leitura de Freud sobre a sexualidade feminina, a demanda sexual desmesurada e o imperativo do amor, colocariam a figura da mulher numa posição anticivilizatória e antissocial, como formulado mais tarde, pelo autor, no trabalho $O$ Mal-Estar na Civilização. A mulher, delineada ao mesmo tempo como agente civilizatório (atuando como mães e educadoras morais) e agente anticivilizatório, entre catalisadora da ordem e operadora da desordem, estaria, assim, polarizada entre a maternidade e o erotismo (BIRMAN, 2001).

Mas, se as condições histórico-culturais influenciam os discursos que circulam em relação à mulher e ao fazer docente e, efetivamente, constroem os sentidos desses mesmos discursos, com a mudança nessas condições, discursos assumidamente androcêntricos tendem a perder sua legitimidade.

No entanto, em alguns domínios, tais discursos continuam a circular. Essas contradições presentes no discurso - já que junto aos atributos "lindas" e "charmosas", agora adjetivos como "corajosas" e "determinadas" e "cheias de amor para dar" agregam-se e marcam o surgimento de um novo tipo de discurso de poder, o discurso mercadológico.

Nesse sentido, Payer (2005) observa a existência de um "enunciado todopoderoso do Mercado" que funciona como lugar de interpelação ideológica (Althusser) do indivíduo em sujeito, que pode ser resumido em uma palavra: "sucesso". "O enunciado do sucesso se imprime através de inúmeros textos, e circula de muitos modos, mas sobretudo através da Mídia" (PAYER, 2005, p. 18).

O sujeito capturado pela injunção do sucesso é aquele que funciona de acordo com a ilusão de completude (ORLANDI, 2000, apud PAYER, 2005). Essa ilusão assume a forma de um sujeito voraz, que tudo quer fazer, saber, ter, ver, tudo quer... na crença (ilusória) de que consiga atingir a plenitude suposta no sucesso. Nota-se, assim, o funcionamento de um ideal de sujeito determinado (PAYER, 2005).

Estabelecendo relações com esse sujeito voraz, o Discurso Capitalista, DC, formulado por Lacan (1992), fabrica um sujeito animado pelo "desejo capitalista" que interpreta sua falta estrutural como "falta a ser rico", produzindo o sujeito inadimplente, descapitalizado, sempre em dívida com os apelos que não lhe cessam de chegar (QUINET, 2012).

Assim, dentre as possíveis armadilhas desse discurso de sucesso, as mulheres, diante das mudanças sociais em que assumem cada vez mais "funções", caracterizadas por um acúmulo de jornada de trabalho e cuidado com a casa e educação dos filhos, tornam-se sujeitos atraídos por esse funcionamento simbólico. $\mathrm{Na}$ "ilusão de completude", as mulheres, professoras, são chamadas a assumirem esse lugar de sujeito determinado e polivalente, impossível de ser alcançado. 


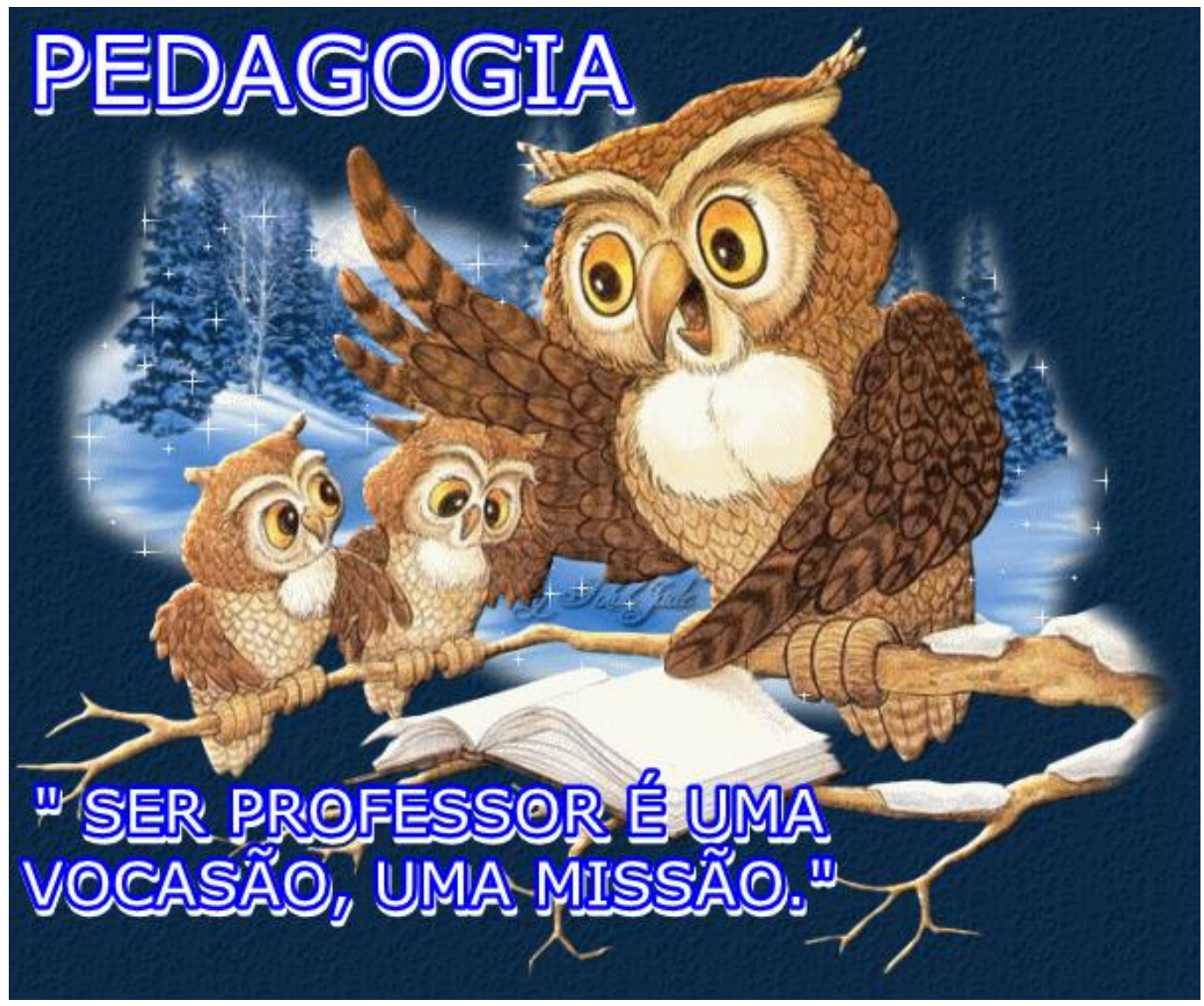

Recorte 2- Imagem retirada do Facebook. Fonte: Professor Por Vocação, 2014.

Caminhando na mesma direção de um atravessamento discursivo entre o ser e fazer docente e o feminino e a ambiguidade da profissão docente, o recorte 2 traz em seu enunciado, ideias relacionadas ao "dom" e à "vocação" para educar, não sendo necessário, portanto, embasamento científico. Um discurso que privilegia a "experiência" de educar, tão arraigada à figura do feminino e da mãe, em detrimento aos campos de conhecimento, entendidos como científicos, que fundamentam a Pedagogia.

Muitas imagens circulantes pela rede social, não sem frequência, remetem a discursos carregados de valores como "dom", "vocação" ou "missão", enraizados na tradição de servir e cuidar, impregnados por uma estreita relação desenvolvida entre o ato de ensinar e as congregações religiosas.

O atravessamento do discurso religioso produz efeito de sentido de que o ato de educar estaria marcado por sentidos de abnegação, renúncia, missão e sacerdócio. Os estudos de Nóvoa (1999) corroboram nosso argumento, pois, segundo o educador português, uma das imagens mais fortes e recorrentes a respeito do professor é a de missionário, a quem caberia ações de doação (amor, atenção, compreensão, conteúdos).

Assim, a profissão de professor enraíza-se fortemente ao fazer ligado ao "dom" ou ao "sacerdócio", inscrevendo essa memória em formações discursivas que naturalizam os discursos atuais. 
De acordo com Nóvoa (1999, p. 15), inicialmente a função docente desenvolveuse de forma subsidiária e não especializada, constituindo uma ocupação secundária de religiosos e leigos das mais diversas origens. Com o processo de estatização do ensino, pretende-se a substituição de professores religiosos por um corpo de professores laicos e sob o controle do Estado, sem, no entanto, modificarem-se as normas e valores originais que aproximam o modelo de professor do modelo de padre (JULIA, 1981, apud NÓVOA, 1999).

Educar, então, seria um "dom", uma "vocação", ideário esse que se fortalece com a ambiguidade (NÓVOA, 1999) do estatuto dos professores e acentua-se com o processo de feminização do professorado (NÓVOA, 1999); processo esse histórico e social, que aproxima a pedagogia e o feminino, tendo como resultado o "espelhamento" do discurso pedagógico e do discurso materno (Recorte 3).

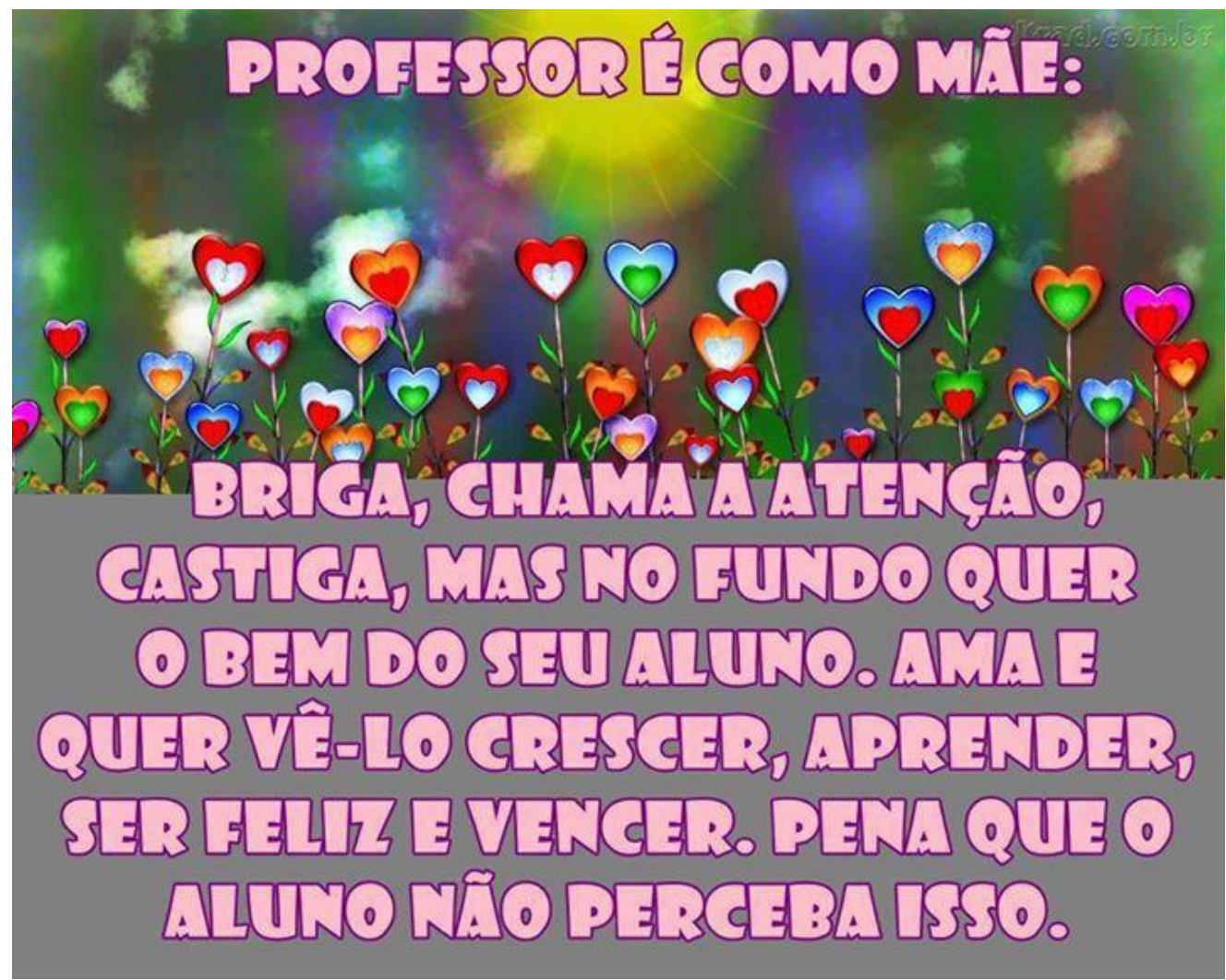

Recorte 3- Imagem retirada do Facebook. Fonte: Profissão Professor, 2013.

Historicamente, foi com a concretização processual dos sentimentos de família, que a infância passa a operar uma espécie de revolução de mentalidade até então vigente. No fim do século XVII, a imagem da mãe, de seu papel e de sua importância, modificase radicalmente, ainda que na prática, os comportamentos tardassem a se alterar (BADINTER, 1985, p. 145).

O amor materno surge como novo valor que significou a promoção do sentimento e também a promoção da mulher enquanto mãe. O foco ideológico passa a destacar cada vez mais a mãe e seu papel desempenhado na família. É o discurso de protagonismo social que seduz e captura as mulheres, como sinalizado por Badinter (1985), já que, durante 
quase dois séculos, os ideólogos lhes prometeram mundos e fundos, se assumissem suas tarefas maternas: "Sede boas mães, e sereis felizes e respeitadas. Tornai-vos indispensáveis na família, e obtereis o direito a cidadania" (p. 147).

Reside aqui, um ponto forte ideologicamente falando. A necessidade de mão de obra barata e farta seria satisfeita usando o trabalho não remunerado da mulher, já que esse era algo considerado próprio de sua natureza (SILVA, 1968, p. 76).

A educação moderna, mesmo situada no tempo histórico atual - em que as instituições e valores se alteram rapidamente - por meio dos discursos circulantes, continua sustentando um modo de educar ordenado, sem abrir mão da tradição ou da autoridade.

A ausência de um corpus conceitual próprio, por se constituir de uma "ciência mestiça" (CHARLOT, 2006), dificulta os limites claros da Pedagogia como campo de conhecimento e formação. Fato que acaba também, por fusionar e dispersar, ao mesmo tempo, os discursos circulantes. "É notório como há uma pregnância do discurso "humano" e "religioso" nas falas e gestos dos profissionais da educação" (PEREIRA, 2008, p. 173).

Há uma confusão sobre uma possível ideia do que possa ser a Pedagogia que, facilmente, se confunde com uma ideia do que possa ser docência. A dispersão conceitual de uma profissão pode gerar uma profusão de discursos, igualmente dispersos, que se configuram desde um saber materno cientifizado (como observado nos recortes destacados anteriormente) a uma defesa vigorosa do aprender na prática da sala de aula (PEREIRA, 2008).

Essa confusão, aqui observada como um “espelhamento" discursivo, também pode ser observado no recorte número 4 , abaixo.

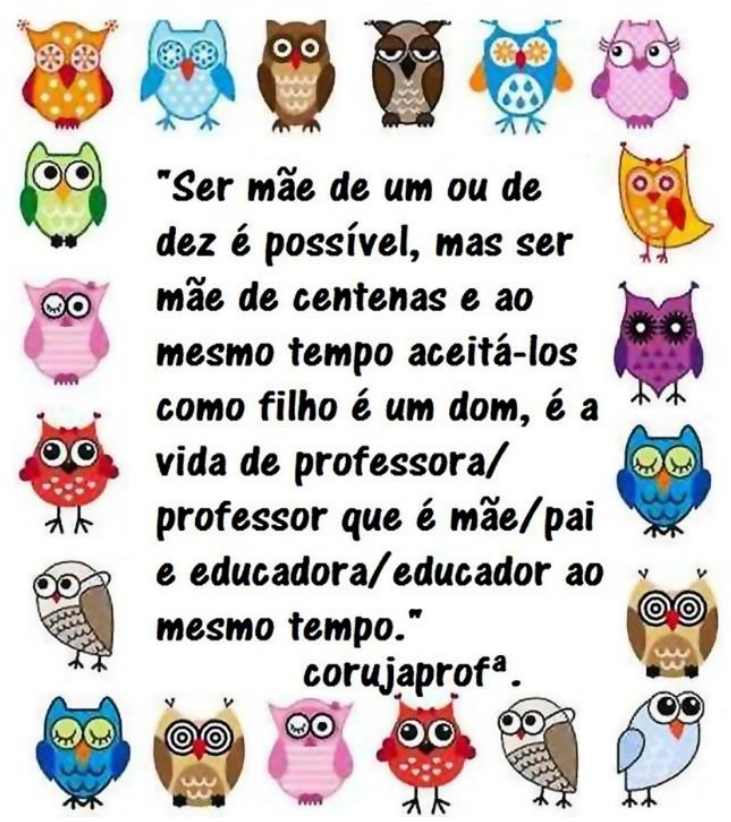

Recorte 4- Imagem retirada do Facebook. Fonte: Coruja Prof ${ }^{a}, 2015$. 
Ao observarmos o recorte número 4, a sequência discursiva "é a vida de professor/professora, que é mãe/pai, educador/educadora ao mesmo tempo", assume que essa forma de ser professor é a única. Embora na sua constituição, inclua as posições também de pai, professor e educador do gênero masculino, as relações com a maternagem na docência ainda são fortemente percebidas, já que no início da formação discursiva, a atenção é toda voltada para a função materna: "ser mãe de um ou de dez é possível, mas ser mãe de centenas e, ao mesmo tempo aceitá-los, é um dom" (grifo nosso). Ser "mãe" de muitos, mais uma vez, é tarefa divina, um dom. E aponta para o que existe de "possível" e (im)possível no ato de educar. Se "ser mãe de um ou dez é possível", educar (centenas) seria algo impossível?

Observamos na sequência citada que "dom" viria como resposta a algo do impossível de educar. É necessário "divinizar" esse fazer, ou cientifizar a maternagem, para criar uma resposta ao que há de impossível no educar.

A Psicanálise, mais uma vez, é quem traz essa (des)construção e contribui para essa reflexão. Há uma afirmação célebre de Freud sobre os ofícios impossíveis, entre os quais estão curar, educar e governar, que se situam na inadequação entre as formulações que se estabelecem e o campo sobre o qual articulam e, por isso, sobressaem como impossíveis com relação a outros ofícios. Todo o esforço de Freud nesse campo pode ser compreendido no sentido de substituir um ideal educativo - concentrado em responder sobre qual a melhor maneira de educar - por uma discussão sobre as condições possíveis de qualquer educação (VOLTOLINI, 2011).

Pereira (2008) chama a atenção para a maternagem não só no sentido da feminização do magistério, mas como uma problemática no cerne da construção da episteme da Pedagogia. Segundo o autor, existe um imaginário em torno de uma Pedagogia idealizada, respaldada em técnicas e didáticas e na defesa de saber-fazer na prática.

Na contemporaneidade, assistimos ao declínio da autoridade e da imagem paterna. A educação não é tarefa apenas da escola (família, mães e pais, televisão, computadores, todos educam). Vivemos em um tempo "racional", "técnológico", cujo saber-fazer foi teorizado. Dessa forma, a maternagem, acabou perdendo seu fôlego. Seu discurso passa a requerer um carimbo científico e a Pedagogia passa a ser essencial para esse propósito.

A pedagogia, sua "maternagem", muito além de seus saberes exclusivamente técnico-racionalistas, demonstra padecer da sombra de se situar entre um sintoma e uma esperança: o sintoma de fazer advir de si mesma o impossível de amestrar, de curar, de educar; e a esperança de elevar o discurso materno, inclusive no que esse guarda de feminização do magistério, à condição de eminentemente científico. Perde-se aí o foco mais fundamental que tal sombra pode oferecer: o de ser o discurso pedagógico, e a "maternagem" que ele engendra, a própria resposta ao impossível. (PEREIRA, 2008, p. 178; grifo do autor)

O autor aponta, ainda, que "entre a adjetivação das epistemologias e a cientifização do saber materno, a pedagogia procrastina a invenção de uma episteme 
própria, capaz de elevar os gestos de suas práticas à categoria de saber teórico" (idem, p. 184).

Arrematando nossas reflexões, com nossos gestos interpretativos (lembramos: não definitivos e inacabados), advindos dos recortes destacados, apontamos para essa dispersão discursiva presente em torno do ser e fazer da profissão docente que circunda, fortemente, aspectos do feminino e da maternagem. Procuramos demonstrar, através dos recortes aqui apresentados, as formações ideológicas e as memórias históricas e discursivas sobre o feminino e o ser e fazer docente presentes, que naturalizam os discursos circulantes na atualidade das redes sociais. Antes de oferecer qualquer fechamento ou solução, através desse movimento analítico, convidamos à abertura reflexiva sobre a subjetivação docente e a novos modos de se pensar e se interrogar a Pedagogia e sua área de atuação, bem como abrir espaço para outras maneiras de se pensar a formação e o fazer docente.

\section{Considerações Finais}

As rápidas transformações no mundo contemporâneo e as novas formas de comunicação e de relações humanas têm se modificado e abarcado outras esferas, tendo grande destaque os espaços virtuais e cibernéticos. Dentre esses, as chamadas redes sociais, são importantes universos de circulação de discursos e sentidos. Olhar nessa direção, portanto, nos parece tarefa fundamental.

Acreditamos no discurso como possibilidade de trazer à tona esse lugar da subjetividade que é o da linguagem e que generosamente produz incontáveis meandros e matizes, sendo, portanto, passível de problematização e (des)construção do evidente, do transparente e do naturalizado. Nesse sentido, a AD e a Psicanálise têm muito a contribuir.

Entre os discursos circulantes sobre a profissão docente, nos inquieta, sobremaneira, o entrelaçamento entre o feminino e o ser e fazer docente. Esse entrelaçamento repousa sobre a dispersão de outros discursos que constituem os domínios da Educação e da Pedagogia.

Dispersão essa que abarca desde princípios religiosos moralizantes, estereótipos de gênero, até a maternagem. Ao voltarmos nosso olhar sobre como o feminino e a docência estão imbricados, como são falados e imaginados, direcionamos nossos esforços para reconhecer as memórias históricas e discursivas que atualizam os discursos atuais e, assim, contribuir para a desnaturalização de sentidos nos discursos produzidos e circulantes no espaço cibernético, especificamente nas redes sociais, mas alcançando, também, assim acreditamos, outras esferas de funcionamento discursivo.

Além disso, buscamos com esse movimento, ainda que timidamente, contribuir para que a Pedagogia possa se interrogar politicamente sobre sua atuação, função e constituição como disciplina e saber teórico (e prático) e, advindo desse deslocamento, que a profissão docente possa ser (re)conhecida e (re)valorizada, incorporando o "impossível" que o ato de educar engendra. 


\section{Referências bibliográficas}

ALMEIDA, J. S. de. Mulher e educação: a paixão pelo possível. São Paulo: UNESP, 1998.

ALTHUSSER, L. Ideologia e Aparelhos Ideológicos de Estado (notas para uma investigação). Em: ADORNO, $\mathrm{T}$ et al. O Mapa da Ideologia. Rio de Janeiro: Contraponto, 1996. pp.105-142.

BADINTER, E. Um amor conquistado: o mito do amor materno. Rio de Janeiro: Nova Fronteira, 1985.

BIRMAN, J. Cartografias do feminino. São Paulo: Ed. 34, 1999.

Gramáticas do erotismo: a feminilidade e suas formas de subjetivação em psicanálise. Rio de Janeiro: Civilização Brasileira, 2001.

BRANDÃO, H. H. N. Introdução à análise do discurso. Campinas: Editora da Unicamp, 2004.

CHARLOT, B. A pesquisa educacional entre conhecimentos, políticas e práticas: especificidades e desafios de uma área de saber. Revista Brasileira de Educação, Rio de Janeiro, v. 11, n. 31, abr. 2006.

CORUJA PROF ${ }^{\mathrm{a}}$ 23 DE MAIO DE 2015. Disponível em https://www.facebook.com/CorujaProf/photos/a.545629065465806.136117.545618312 133548/1081395018555872/?type=1; acessado em: 24 de maio 2015.

FREUD, S. Estudos sobre a histeria. Em: Obras psicológicas completas de Sigmund Freud. Edição Standard Brasileira. Vol. 2. Rio de Janeiro: Imago, 2006.

LACAN, J. O Seminário, livro 17: O avesso da Psicanálise. Rio de Janeiro: Jorge Zahar, 1992.

O Seminário, livro 2: $O$ eu na teoria de Freud e na técnica da Psicanálise. Rio de Janeiro: Jorge Zahar, 1995.

Escritos. Rio de Janeiro: Jorge Zahar, 1998.

MAGGI, N. R. Subjetividade e Intersubjetividade: o olhar da psicanálise. Em: FOLBERG, M. N. et al (Org.). Desdobrando o avesso da Psicanálise: relações com a educação. Porto Alegre: MNF; Evangraf, 2002. pp. 91-97.

MARIANI, B. Subjetividade e imaginário linguístico. Linguagem em (Dis)curso. Tubarão, v. 3, número especial, pp. 55-72, 2003. Disponível em http://www.portaldeperiodicos.unisul.br/index.php/Linguagem_Discurso/article/viewFil e/246/261; acessado em maio 2014. 
MOREIRA, R. de C. C. Mulheres, educação e maternagem. Anais Eletrônicos do IX Seminário Nacional de Estudos e Pesquisas - História, Sociedade e Educação no Brasil. UFPB, João Pessoa, julho/agosto 2012. pp. 3220-3231. Disponível em http://www.histedbr.fe.unicamp.br/acer_histedbr/seminario/seminario9/PDFs/4.17.pdf; acessado em jun. de 2015.

NÓVOA, A. O passado e o presente dos professores. Em: NÓVOA, A. et al. (Orgs.). Profissão Professor. Portugal: Porto Editora, 1999. pp. 13-33.

ORLANDI, E. P. Análise do discurso: princípios e procedimentos. Campinas: Pontes editores, 2012. 1987.

A linguagem e seu funcionamento: as formas do discurso. Campinas: Pontes,

PAYER, M. O. Linguagem e sociedade contemporânea: sujeito, mídia e mercado. RUA [Revista do Núcleo de Desenvolvimento da Criatividade da Unicamp], LABEURB, NUDECRI. Campinas, São Paulo, n. 11, pp. 9-25, mar. 2005.

PEREIRA, M. R. A impostura do mestre. Belo Horizonte: Argvmentvm, 2008.

PEUCHÊUX, M. Papel da memória. Em: ACHARD, Pierre et al. Papel da memória. Trad. Bras. Campinas: Pontes, 2010. pp. 49-56.

Discurso: estrutura ou acontecimento. Trad. Bras. Campinas: Pontes, 1999.

Semântica e Discurso: uma crítica à afirmação do óbvio. Trad. Bras. Campinas, SP: Ed. da UNICAMP, 1995.

PINSKY, C. B. Mulheres dos anos dourados. São Paulo: Contexto, 2014.

PROFESSORES CRIATIVOS. 2 de mar. 2015. Disponível em https://www.facebook.com/superprofessoracriativa/photos/a.1517042438534312.10737 41828.1468523920052831/1593426214229267/?type=1; acessado em ago. 2015.

PROFESSOR POR VOCAÇÃO. 27 de fev. de 2014. Disponível em https://www.facebook.com/495796167197879/photos/a.495805307196965.1073741828 $.495796167197879 / 510340712410091 /$ ?type=1; acessado em set. 2015.

PROFISSÃO PROFESSOR. 11 de nov. de 2013. Disponível em https://www.facebook.com/329222423788535/photos/a.329813757062735.80712.3292 22423788535/673349869375787/?type=1; acessado em maio 2015 .

QUINET, A. Os outros em Lacan. Rio de Janeiro: Zahar, 2012.

SILVA, E. M da. As relações de gênero no magistério: a imagem da feminização. Vitória: Edufes, 2002.

SOLER, C. O que Lacan dizia das mulheres. Rio de Janeiro: Zahar, 2005. 
TFOUNI, L.V. O dado como indício e a contextualização do (a) pesquisador (a) nos estudos sobre a compreensão da linguagem. REVISTA D.E.L.T.A., v. 8, n. 21992.

TFOUNI, F. E. V., TFOUNI, L. V. Entra burro; sai ladrão: o imaginário sobre a escola materializado nos genéricos. Linguagem em (Dis)curso, Tubarão, v. 7, n. 2, pp. 293311, maio/ago. 2007.

Letramento e Alfabetização. São Paulo: Cortez, 2010.

VOLTOLINI, R. Educação e Psicanálise. Rio de Janeiro: Zahar, 2011.

$* * *$

Artigo recebido em: setembro de 2015

Aprovado e revisado em: fevereiro de 2016.

Publicado em: março de 2016

Para citar este texto:

DORNELAS, Camila Carrari; ASSOLINI, Filomena Elaine P. A discursivização do feminino e suas relações com a docência: memória e atravessamentos discursivos. Entremeios [Revista de Estudos do Discurso], Seção Estudos, Programa de Pós-graduação em Ciências da Linguagem (PPGCL), Universidade do Vale do Sapucaí, Pouso Alegre (MG), vol. 12, p. 45-64, jan. - jun. 2016.

DOI: http://dx.doi.org/10.20337/ISSN2179-3514revistaENTREMEIOSvol12pagina45a64 